\section{Commentary: Are 10,000 hours really the key to adult learning? Perhaps not}

\author{
Qimeng Gao, MD, ${ }^{\mathrm{a}}$ and Matthew G. Hartwig, $\mathrm{MD}^{\mathrm{b}}$
}

The coronavirus disease 2019 (COVID-19) pandemic significantly impacted postgraduate training globally, especially in procedure-based surgical specialties. ${ }^{1-4}$ This is reflected as a significant reduction in case volumes. In a survey conducted by the Thoracic Surgery Resident's Association, more than $50 \%$ trainees reported at least a $50 \%$ reduction of their case volumes since the beginning of the pandemic, and $25 \%$ believed that their operative experience had essentially been eliminated. ${ }^{5}$

Simulation has long been recognized as an integral part of surgical education, especially for entry-level and junior trainees. ${ }^{6,7}$ With such a dramatic reduction in operative volume during the COVID-19 pandemic, simulation could potentially fill the gap and expand educational opportunities in procedures skills while maintaining social-distancing protocols. ${ }^{8-11}$

In this issue of the Journal, Chan and colleagues ${ }^{12}$ described a simple, low-fidelity vascular anastomosis model to simulate left atrial and pulmonary artery cuffs during lung transplantation, in combination with individual video coaching and virtual skills teaching sessions. This study is unique in that it targeted only advanced learners. All trainees included have completed at least 7 years of surgical training and performed/assisted more than 25 cases of lung transplant. Traditionally, simulations are designed to highlight the essential steps and

From the ${ }^{\mathrm{a}}$ Department of Surgery and ${ }^{\mathrm{b}}$ Division of Cardiovascular and Thoracic Surgery, Duke University Medical Center, Durham, NC.

Disclosures: Dr Hartwig consults for Bridge to Life, Paragonix, Medtronic, Biomedinnovations, and Intuitive Surgical. Dr Gao reported no conflicts of interest.

The Journal policy requires editors and reviewers to disclose conflicts of interest and to decline handling or reviewing manuscripts for which they may have a conflict of interest. The editors and reviewers of this article have no conflicts of interest.

Received for publication Aug 21, 2021; revisions received Aug 21, 2021; accepted for publication Sept 10, 2021; available ahead of print Sept 28, 2021.

Address for reprints: Matthew G. Hartwig, MD, Division of Cardiovascular and Thoracic Surgery, Duke University Medical Center, Box 3863, Durham, NC 27710 (E-mail: matthew.hartwig@duke.edu).

JTCVS Open 2021;8:688-9

2666-2736

Copyright (C) 2021 The Author(s). Published by Elsevier Inc. on behalf of The American Association for Thoracic Surgery. This is an open access article under the CC BY-NC-ND license (http://creativecommons.org/licenses/by-nc-nd/4.0/).

https://doi.org/10.1016/j.xjon.2021.09.009

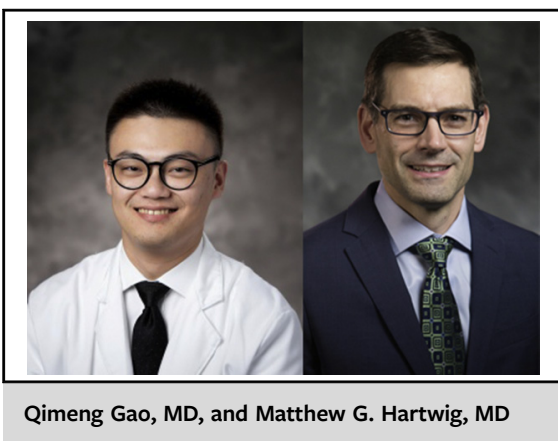

CENTRAL MESSAGE

A significant reduction in operative volume during the COVID-19 pandemic impacted surgical training. Simulation could be used to maintain and further develop procedure skills even in advanced learners.

familiarize learners with instruments. In this case, the curriculum focused on advanced surgical techniques, efficiency, and economy of motion. In addition, the model can be modified to simulate specific challenging scenarios, such as a short cuff or a deep chest. After spending an average of 5 hours practicing on the model within a 3month period, most reported an increased confidence in performing a lung transplant. Upon resumption of clinical activities, warm ischemic time, which was used as a rough proxy to anastomosis time, was equivalent compared with that before the lockdown period. Interestingly, the study subject that spent the most amount of time with the curriculum actually had a statistically significant decrease in warm ischemic time.

Despite the limitation on sample size and risk of internal bias, the study demonstrated a potential role of simulation among the advanced learners. It is important to recognize a shift in learning objectives when it comes to advanced learners. Unlike for junior residents, for whom simulation tends to be proficiency based, simulation for advanced learners aims at fine-tuning advanced skills through selfpractice, group practice, and feedback from peers/staff surgeons. The model does not necessarily have to recreate the operating room, as advanced learners have encountered it before. To these learners, the simulation platform instead provides a safe environment to try out a new technique and to optimize efficiency. 
Ultimately, the proposed virtual curriculum can also be expanded beyond the COVID-19 era. Trainees taking time out of training could maintain and develop surgical skills through simulation, and trainees in programs in which there is a shortage of complex procedures could benefit from simulation on certain specific skills.

\section{References}

1. Purdy AC, de Virgilio C, Kaji AH, Shields Frey E, Lee-Kong S, Inaba K, et al. Factors associated with general surgery residents' operative experience during the COVID-19 pandemic. JAMA Surg. 2021;156:767-74.

2. Kogan M, Klein SE, Hannon CP, Nolte MT. Orthopaedic education during the COVID-19 pandemic. J Am Acad Orthop Surg. 2020;28:e456-64.

3. Crosby DL, Sharma A. Insights on otolaryngology residency training during the COVID-19 Pandemic. Otolaryngol Head Neck Surg. 2020;163: $38-41$.

4. Cho DY, Yu JL, Um GT, Beck CM, Vedder NB, Friedrich JB. The early effects of COVID-19 on plastic surgery residency training: the University of Washington experience. Plast Reconstr Surg. 2020;146:447-54.

5. Smood B, Spratt JR, Mehaffey JH, Luc JGY, Vinck EE, Lehtinen ML, et al. COVID-19 and cardiothoracic surgery: effects on training and workforce utilization in a global pandemic. J Card Surg. 2021;36: 3296-305.

6. Sutherland LM, Middleton PF, Anthony A, Hamdorf J, Cregan P, Scott D, et al. Surgical simulation: a systematic review. Ann Surg. 2006;243:291-300.

7. Enter DH, Lee R, Fann JI, Hicks GL Jr, Verrier ED, Mark R, et al. “Top Gun” competition: motivation and practice narrows the technical skill gap among new cardiothoracic surgery residents. Ann Thorac Surg. 2015;99:870-5; discussion 875-6.

8. Jarry Trujillo C, Achurra Tirado P, Escalona Vivas G, Crovari Eulufi F, Varas Cohen J. Surgical training during COVID-19: a validated solution to keep on practicing. Br J Surg. 2020;107:e468-9.

9. McKechnie T, Levin M, Zhou K, Freedman B, Palter VN, Grantcharov TP, et al. Virtual surgical training during COVID-19: operating room simulation platforms accessible from home. Ann Surg. 2020;272:e153-4.

10. Perez-Escamirosa F, Medina-Alvarez D, Ruiz-Vereo EA, Ordorica-Flores RM Minor-Martínez A, Tapia-Jurado J, et al. Immersive virtual operating room simulation for surgical resident education during COVID-19. Surg Innov. 2020;27: 549-50.

11. Naughton A, Higham A, Ong AY, Wasik M. Surgical simulation training is crucial in the covid-19 era and beyond. BMJ. 2021;373:n1301.

12. Chan JCY, Waddell TK, Yasufuku K, Keshavjee S, Donahoe L. Maintaining technical proficiency in senior surgical fellows during the COVID-19 pandemic through virtual teaching. J Thorac Cardiovasc Surg Open. 2021; 8:679-87. 